\title{
Prognostic role of the tumor-associated tissue inflammatory reaction in transitional bladder cell carcinoma
}

\author{
TOMMASO CAI ${ }^{1}$, GABRIELLA NESI $^{2}$, VIERI BODDI $^{3}$, SANDRA MAZZOLI $^{4}$, \\ MAURIZIO DAL CANTO ${ }^{1}$ and RICCARDO BARTOLETTI ${ }^{1}$ \\ Departments of ${ }^{1}$ Urology, ${ }^{2}$ Pathology and Oncology, ${ }^{3}$ Public Health and Epidemiology, \\ University of Florence; ${ }^{4}$ STDs Center, Santa Maria Annunziata Hospital, Florence, Italy
}

Received January 16, 2006; Accepted March 15, 2006

\begin{abstract}
Many authors have indicated that the presence of an inflammatory response within the tumor may predict not only recurrence and progression but also survival in several tumors, including transitional cell carcinoma (TCC) of the urinary bladder. Several studies have been performed with a mean follow-up period that is often too limited for predicting patient outcome. The aim of the present study was to define the influence of inflammatory cell infiltrate on recurrence, progression and survival in TCC of the bladder over a long follow-up period. Between January and December 1995, 410 consecutive patients, who had undergone transurethral or open surgery for bladder tumors at the same urologic center, were selected for the study. All cases were reviewed to assess histotype, stage and grade of the tumor and presence or absence of tumor-associated inflammatory reaction. To better evaluate the prognostic role of each single factor in TCC, a follow-up of 10 years after surgery was performed. Pathologic evaluation showed superficial TCC in 312 patients, while 98 had an invasive bladder tumor. Three among 410 bladder tumors were squamous cell carcinomas. Out of 407 TCCs, 119 (29.23\%) presented inflammation within the tumor or the lamina propria. At 10 years follow-up, a statistically significant association was shown between the presence of inflammation within the tumor or lamina propria and the number of recurrences $(p<0.0001)$. Moreover, the absence of inflammatory infiltrate in the tumor established the relative risk of suffering more than one recurrence at 2.287 (95\% CI 1.180-3.346). The Mann-Whitney test confirmed a statistically significant difference between superficial bladder tumors with inflammation and those without (26.3 vs 11.5 months, $\mathrm{p}<0.001)$. In terms of survival rate, a statistically significant difference was
\end{abstract}

Correspondence to: Dr Tommaso Cai, Department of Urology, University of Florence, Via dell' Antella 58, 50011 Bagno a Ripoli, Florence, Italy

E-mail: ktommy@libero.it

Key words: transitional cell carcinoma, bladder cancer, recurrence, prognostic factors, inflammatory cells reported between carcinomas with and without inflammation $(\mathrm{p}=0.0261)$. On multivariate analysis, the presence of inflammation within the tumor was found to be an independent predictor of survival in patients with TCC of the bladder $(p=0.027)$. Survival analysis by means of the Kaplan-Meier curves showed a statistically significant difference between patients with tumor-associated inflammatory reaction and those without $(p=0.0098)$. These results confirm that the presence of inflammatory reaction has a good prognostic value in transitional bladder cell carcinoma. However, to better define its prognostic significance, the characterization of inflammatory cells in tumor-associated tissue reaction must be accomplished.

\section{Introduction}

Transitional cell carcinoma (TCC) of the urinary bladder displays heterogeneous clinical behavior. Histologic grade and disease stage are well-defined prognostic indicators, but are not always useful in predicting outcome in individual cases $(1,2)$. Tumor configuration, multiplicity, size, coexistent carcinoma in situ (CIS) and overexpression of genes and gene products may have prognostic significance in certain situations (3-10). In the attempt to better define the natural history of TCC, the significance of angiogenesis was also evaluated, but with no certain role in predicting patient outcome (11). Many authors have demonstrated a correlation between increased vascularization and poor clinical outcome (12). However, a positive correlation between inflammation in the tumor, angiogenic factors and good prognosis was described by Offersen et al (13). More recently, the presence of inflammatory response within the tumor has been shown to predict not only recurrence and progression, but also survival in patients with TCC (14-16). The fact that inflammation plays a primary role in host reaction to the tumor has also been widely emphasized in other neoplasms (17). Indeed, in a study published in 1936 by McCarty, the presence in colon cancer of intense inflammation, and lymphocytic infiltrate in particular, correlated with a good prognosis (18). In a more recent study carried out on 156 patients undergoing gastric resection for stomach cancer, Takeuchi proved that natural killer (NK) cell activity is an independent parameter of good prognosis (19). In TCC, the significance of inflammation has been analyzed in the literature with a mean follow-up period 


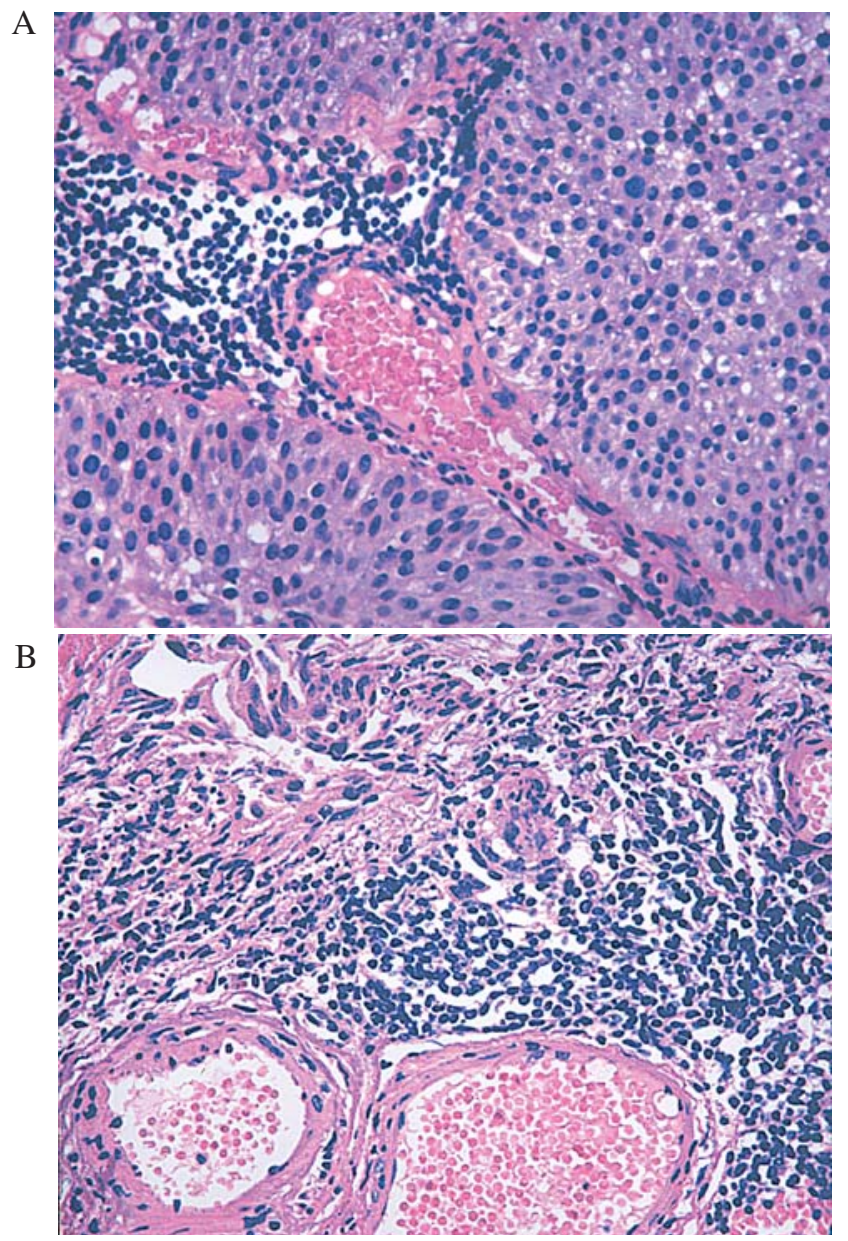

Figure 1. (A) Prominent lymphoid infiltrate is seen around the vessels and near the surface of a non-invasive TCC. (B) Intense inflammatory reaction is evident in the lamina propria around invasive islets of tumor tissue.

that is often too limited for the prediction of patient outcome. The aim of this study was to ascertain the influence of inflammatory cell infiltrate on recurrence, progression and survival in TCC of the bladder over a long follow-up period.

\section{Materials and methods}

Study design. To evaluate the prognostic significance of tumorassociated tissue inflammatory reaction in transitional bladder cell carcinoma, 410 consecutive patients, who had undergone surgical treatment [transurethral resection (TUR) or open surgery] for bladder carcinoma at the Urologic Unit of the University of Florence between January and December 1995, were selected for the study.

Inclusion criteria. All patients who reported cystoscopically demonstrated bladder tumors and who gave their informed consent to comply with the follow-up schedule were selected for the study.

Exclusion criteria. All patients with a history of TCC of the upper urinary tract, those who had undergone surgery for benign prostatic obstruction at the same time as surgical treatment for TCC, and those with a history of prostate or other urologic cancers were excluded.
Table I. Pathologic data of 410 bladder tumors.

\begin{tabular}{lrrrrr}
\hline & \multirow{2}{*}{ TNM stage } & \multicolumn{3}{c}{ Grade } & Total \\
\cline { 3 - 5 } & & G1 & G2 & G3 \\
\hline \multirow{2}{*}{ TCC } & pTa & 155 & 88 & 14 & 257 \\
& pT1 & 1 & 19 & 30 & 50 \\
& pT2 & 0 & 2 & 43 & 45 \\
& pT3 & 0 & 3 & 32 & 35 \\
& pT4 & 0 & 0 & 15 & 15 \\
Total & & 156 & 112 & 134 & 402 \\
& & & & & \\
SCC & pTis & & & & 5
\end{tabular}

Total

Distribution of 410 bladder tumors according to stage and grade. TCC, transitional cell carcinoma; SCC, squamous cell carcinoma.

Histopathology. All cases were reviewed on the basis of the available slides in order to evaluate histotype, stage and grade of the tumor, presence or absence of tumor-associated inflammatory reaction and characteristics of lymphocytic infiltrate. Specimens were pathologically staged according to the TNM classification of the International Union Against Cancer (UICC) (20) and the grade was assessed following the World Health Organization (WHO) scale (21). The presence or absence of mononuclear infiltrates within the tumor was evaluated in all cases. Tumor-associated inflammatory reaction was considered to be present when a gathering of $>20$ lymphocytes, at times mixed with plasma cells and polymorphonuclear leukocytes, was observed in at least one low-power (x40) field per section (Fig. 1).

Patient follow-up. Each patient was followed up in relation to the clinicopathologic characteristics of the tumor, in accordance with the European Association of Urology Guidelines of Bladder Cancer (22). Mean follow-up was 90 months (ranging from 84 to 96 months). On consideration of data from the literature, it was thought appropriate to carry out a long-term follow-up, so as to better determine the prognostic factors of recurrence, progression and disease-specific mortality (23). Recurrence was determined on the basis of papillary formations protruding into the bladder lumen and detected on cystoscopy, or the presence of neoplastic tissue diagnosed after vesical biopsy. Progression was defined as an increase in tumor stage or grade.

Statistical analysis. Pearson's coefficient was adopted to evaluate the correlation between the different parameters in both superficial and invasive bladder cancer patients, and Fisher's exact test was used to assess statistical significance with $\mathrm{p}<0.05$ accepted as significant. The Mann-Whitney test was also performed to compare different parameter mean values. The ANOVA test was used for univariate analysis 
and the log-rank test (Mantel Cox) for multivariate analysis. Kaplan-Meier survival curves were also used to estimate survival. All statistical analyses were performed using SPSS 11.5 for Windows (SPSS, Inc. Chicago, Illinois).

\section{Results}

Patients' clinicopathologic characteristics. Of the 410 patients recruited for the study, 306 were male $(74.6 \%)$ and 104 were female $(25.3 \%$ ). Patient age ranged from 32 to 93 (mean, 68.89 years). At least one recurrence was experienced by 83 of the 410 patients $(20.4 \%)$, whilst the remaining 327 (79.6\%) were diagnosed for the first time with bladder cancer. Ten of the patients with recurrence presented disease progression from pTa to pT1 $(8.3 \%)$ and 22 patients had progression from superficial to invasive disease $(26.5 \%)$. A TUR of the tumor was performed on 316 patients $(77.03 \%)$ and radical cystectomy with urinary diversion on 94 (22.97\%). Pathologic examination gave the following results: out of the 410 tumors analyzed, 407 were TCCs (99.26\%) and 3 were squamous cell carcinomas $(0.74 \%)$. Histologic data are detailed in Table I. In one case, CIS was associated with pT1G3. Pathologic assessment of lyxmph node status gave $6 \mathrm{Nx}$ (3 pT1, 3 pT4a), 36 N0 (1 pTa, 7 pT1, 11 pT2, 15 pT3, 2 pT4), 7 N1 (1 pT2, 5 pT3, 1 pT4) and 7 N2 (3 pT2, 3 pT3, 1 pT4). Among the patients undergoing TUR, 201 received adjuvant treatment for 6 weeks with weekly bacillus Calmette-Guerin (BCG) instillations $(63.6 \%)$ at an average interval of 21 days after the operation. Adjuvant treatment with different chemotherapeutic agents was administered to 86 patients $(27.5 \%)$ but 29 patients were not given any adjuvant intravesical therapy $(8.8 \%)$.

Tumor-associated tissue inflammatory reaction analysis. Inflammation within the tumor or the lamina propria was found in 119 of the 407 patients with TCC (29.23\%). Of these, 99 had superficial lesions $(83.19 \%)$ and 20 had invasive lesions (16.81\%). Among the invasive tumors, one of the patients with positive lymph nodes exhibited pronounced inflammatory infiltrate in the tumor and lamina propria, whereas only one of the three squamous cell carcinomas presented inflammation within the tumor (Table II). Intense inflammatory reaction was present in superficial and invasive tumors, $31.13 \%$ and $21.73 \%$ respect-ively. Even though inflammation occurred more frequently in superficial tumors, no statistically significant difference was noted $(\mathrm{p}=0.0904)$.

\section{Statistical analysis on superficial bladder cancers}

Recurrence. Overall, 174 of the 318 superficial tumors presented only one recurrence $(54.71 \%)$, whilst 144 patients presented two or more recurrences $(45.29 \%)$. Among the 99 superficial tumors with inflammation, 73 (73.73\%) had one recurrence, while the other $26(26.27 \%)$ had two or more. Among the 219 patients with superficial tumors and no inflammatory reaction, 101 experienced one recurrence (46.11\%), whilst 118 had two or more (53.89\%). A statistically significant relationship was shown between the presence of inflammation within the tumor or lamina propria and the number of recurrences $(p<0.0001)$. Indeed, the absence of inflammatory infiltrate in the tumor established
Table II. Bladder tumor distribution according to the presence of inflammatory infiltrate.

\begin{tabular}{|c|c|c|c|c|c|}
\hline & & & \multicolumn{2}{|c|}{ Inflammation } & \multirow[t]{2}{*}{ Total } \\
\hline & & & Absent & Present & \\
\hline \multirow{8}{*}{ TNM stage } & TCC & pTa & 168 & 89 & 257 \\
\hline & & pT1 & 40 & 10 & 50 \\
\hline & & pT2 & 34 & 11 & 45 \\
\hline & & pT3 & 28 & 7 & 35 \\
\hline & & pT4 & 13 & 2 & 15 \\
\hline & & pTis & 5 & 0 & 5 \\
\hline & $\mathrm{SCC}$ & pT3 & 2 & 1 & 3 \\
\hline & Total & & 290 & 120 & 410 \\
\hline \multirow[t]{4}{*}{ Grade } & $\mathrm{TCC}$ & G1 & 116 & 40 & 156 \\
\hline & & $\mathrm{G} 2$ & 61 & 51 & 112 \\
\hline & & G3 & 106 & 28 & 134 \\
\hline & Total & & 283 & 119 & 402 \\
\hline
\end{tabular}

Presence of inflammatory infiltrate in all bladder carcinomas according to stage and in TCC of the urinary bladder according to grade. TCC, transitional cell carcinoma; SCC, squamous cell carcinoma.

the relative risk of suffering more than one recurrence at $2.234(95 \%$ CI 1.574 - 3.430).

Disease-free interval. Correlating the presence of tumorassociated inflammatory reaction with the interval free from disease, the average time before the first recurrence of all superficial tumors was 18.9 months. Superficial bladder tumors with inflammation had an average time lapse of 26.3 months before the first recurrence. Carcinomas without inflammation had a mean interval of time to the first recurrence of 11.5 months. The Mann-Whitney test confirmed that this difference was statistically significant $(\mathrm{p}<0.0001)$.

Progression. Of the 318 superficial tumors, 8 pTa (5 G3 and $3 \mathrm{G} 2)$ progressed to $\mathrm{pT} 1 \mathrm{G} 3$, whereas $12 \mathrm{pT} 1$ and $1 \mathrm{pTa}(10$ pT1G3, 2 pT1G2, 1 pTaG2) progressed to invasive carcinomas. No correlation was found between the presence of inflammatory reaction within the tumor and stage or grade progression.

Survival rate. With regard to the superficial lesions, 18 patients died from tumors (5.66\%), 66 died from causes unrelated to the tumor and 234 are currently alive with no evidence of disease. Of the 18 patients who died from tumors $(10$ pT1G3, 1 pT1G1, and 7 pTaG3) (mean survival 43.3 months), only two presented areas of inflammation associated with the tumor $(2$ pT1G3). These two patients survived for 67 and 61 months (mean survival, 64 months). The Mann-Whitney test for comparing 
Table III. Multivariate analysis of factors affecting survival in 407 TCCs.

\begin{tabular}{|c|c|c|c|}
\hline $\begin{array}{l}\text { Categories } \\
\text { (variables) }\end{array}$ & $\begin{array}{c}\text { No. of patients } \\
(\%)\end{array}$ & $\begin{array}{c}\text { No. of survivals } \\
(\%)\end{array}$ & $\begin{array}{c}\text { Multivariate analysis } \\
\mathrm{p}\end{array}$ \\
\hline Presentation & & & 0.329 \\
\hline First occurrence & $323(79.36)$ & $211(65.32)$ & \\
\hline Recurrence & $84(20.64)$ & $53(63.09)$ & \\
\hline Number of lesions & & & 0.810 \\
\hline Single & 377 (92.62) & $246(65.25)$ & \\
\hline Multiple & $30(7.38)$ & $18(60.00)$ & \\
\hline Stage & & & $<0.001$ \\
\hline pTis & $5(1.22)$ & $3(60.00)$ & \\
\hline pTa & $257(63.14)$ & $187(72.76)$ & \\
\hline pT1 & $50(12.28)$ & $38(76.00)$ & \\
\hline pT2 & $45(11.05)$ & $33(73.33)$ & \\
\hline pT3 & 35 (8.59) & $3(8.05)$ & \\
\hline pT4 & $15(3.72)$ & $0(-)$ & \\
\hline Grade $^{a}$ & & & $<0.001$ \\
\hline G1 & $156(38.80)$ & $115(73.71)$ & \\
\hline G2 & $112(27.86)$ & $86(76.78)$ & \\
\hline G3 & $134(33.34)$ & $60(44.77)$ & \\
\hline Associated CIS & 1 & - & N.E. \\
\hline Inflammation & & & 0.027 \\
\hline With inflammation & $119(29.23)$ & $87(73.10)$ & \\
\hline Without inflammation & $288(70.77)$ & $177(61.45)$ & \\
\hline Adjuvant therapy after TUR ${ }^{\mathrm{b}}$ & & & 0.038 \\
\hline Administered & 287 (90.82) & 197 (68.64) & \\
\hline Not administered & $29(9.18)$ & $19(65.51)$ & \\
\hline Number of recurrences & & & 0.390 \\
\hline 1 & $173(54.74)$ & $157(90.75)$ & \\
\hline$\geq 2$ & $143(45.26)$ & $87(60.83)$ & \\
\hline
\end{tabular}

Multivariate analysis of overall patient survival in 407 patients with TCC of the urinary bladder. ${ }^{\mathrm{a}}$ Grade: pTis excluded. ${ }^{\mathrm{b}}$ Adjuvant therapy: only in patients undergoing transurethral resection; 201 BCG, 86 chemotherapeutic drugs. N.E., cannot be evaluated.

mean values showed a statistically significant difference between these two populations $(\mathrm{p}=0.0261)$.

\section{Statistical analysis on invasive bladder cancers}

Survival rate. Concerning the 92 patients with invasive carcinoma, $48(50.5 \%)$ died from disease progression, 11 died from causes unrelated to the disease and $36(37.8 \%)$ were still alive and on follow-up. Of the last group, 14 patients showed disease progression and were subjected to treatment other than surgical. Of the 20 patients with inflamed invasive carcinoma, 9 were alive and disease-free, 9 died from the disease and 2 died from other causes. Among the cases with no sign of inflammation, 27 patients were alive with no evidence of disease, 39 died from cancer and 9 from other causes. No statistically significant correlation was noted between survival and the presence of inflammation in invasive carcinomas.
Multivariate analysis using the ANOVA model selected stage and grade as independent determinants of prognosis (stage $\mathrm{p}<0.001$, grade $\mathrm{p}<0.001$ ). Furthermore, the presence of inflammation within the tumor proved to be an independent predictor of survival in patients with TCC of the bladder $(\mathrm{p}=0.027)$ (Table III). Survival analysis by means of the Kaplan-Meier curves showed a statistically significant difference between patients with tumor-associated inflammatory reaction and those without $(\mathrm{p}=0.0098)$ (Fig. 2).

\section{Discussion}

Recent data have indicated that inflammation is a critical component of tumor development and progression (24). A fundamental stage in progression towards widespread disease is the potential of neoplastic cells to divert host immune 


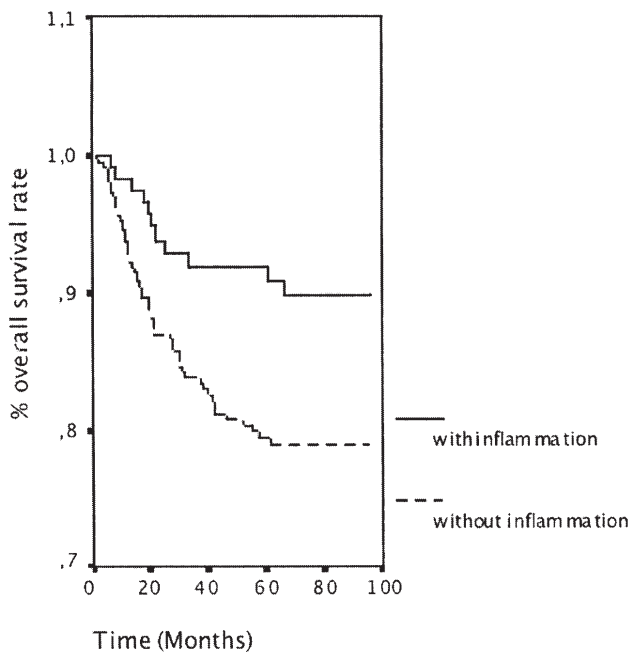

Figure 2. Kaplan-Meier curves illustrating the association between inflammatory reaction within the tumor and overall patient survival. Only patients with TCC were analyzed ( $\mathrm{p}=0.0098 ;$ HR, 2.287; 95\% C.I, 1.180-3.346).

response (25). Indirect proof of the interaction between the tumor and the immune system is the frequent finding within the tumor of diverse leukocyte populations, including lymphocytes and macrophages. The presence of inflammatory infiltrate is thought to indicate an active host response against cancer cells, as has also been seen in TCC of the bladder. In a retrospective analysis on 428 patients, Flamm focused on the correlation between the presence of inflammatory reaction associated with TCC and the lower incidence of diseasespecific deaths (26). Similarly, it was demonstrated by other authors that the presence of inflammatory infiltrate within the tumor correlates with fewer recurrences and cancer-related deaths $(27,28)$. Further indirect proof that host immune response can favorably modify the course of TCC comes from the efficacy of intravesical treatment with BCG, which actively recruits T lymphocytes (29).

Our study highlighted that the presence of tumor-associated tissue inflammatory reaction significantly correlated with a smaller number of recurrences in superficial bladder carcinoma $(\mathrm{p}<0.0001)$ and a prolonged disease-free interval $(\mathrm{p}<0.0001)$. The fact that no relationship could be found between the presence of inflammatory reaction and progression in superficial tumors was, in all likelihood, due to the paucity of data. Survival analysis, performed using Kaplan-Meier curves, also showed a statistically significant difference between tumors with and without inflammation $(\mathrm{p}=0.0098)$ (Fig. 2). On multivariate analysis, tumor-associated tissue inflammatory reaction proved to be an independent prognostic variable $(\mathrm{p}=0.027)$, together with other well-known indicators of clinical outcome (stage $\mathrm{p}<0.001$ and grade $\mathrm{p}<0.001$ ). In a previous study, we reported a strong correlation between peritumoral neoangiogenesis and improved survival in superficial $\mathrm{TCC}^{30}$, demonstrating that this correlation may be due to the angiogenic stimulation of a local inflammatory reaction generated by the host against superficial bladder cancer, as suggested by Offersen et al (13). Moreover, we found that inflammatory reaction occurred more frequently in superficial rather than invasive carcinomas, giving rise to the hypothesis of a substantial deficiency in the host immune response against invasive tumors (30). As many studies have shown, this could depend on several factors inherent in both the tumor and the host. Tumor cells may produce various cytokines such as TGF- $\alpha$ and IL-10, secrete autocrine growth factors such as IL-6, TNF and IL-10, and alter the CD3- $\zeta$ chain expression. In addition, alterations in the host's recruitment of macrophages and antigen presenting cells, together with the expansion of the T suppressor lymphocyte population, can be observed. In a study performed on 146 patients subjected to gastric resection for carcinoma, Ishigami demonstrated that it is the whole lymphocytic population that has an impact on prognosis and not just single subpopulations such as NK cells (31). Our study did not take into account the different cell populations in tumor-associated tissue inflammatory reaction, though the characterization of inflammatory cells in TCC may help in better perceiving the functional relationship between inflammation and cancer. To improve our understanding of the biologic behavior of bladder TCC, a more thorough analysis of host immune reaction would be helpful for a tailored therapeutic strategy which would modify the disease course and reap benefits in terms of survival and quality of life.

Our findings revealed the significant prognostic role of inflammatory reaction in TCC of the urinary bladder and demonstrated that active host immune response against the tumor is a valuable indicator of clinical outcome. In order to better elucidate the mechanisms linking inflammation with a good prognosis in TCC, the characterization of inflammatory cells in tumor-associated tissue reaction must be accomplished.

\section{Acknowledgements}

Special thanks to Professor John Denton for manuscript language revision and to Serena Migno for her help in study design and support.

\section{References}

1. Kurth KH, Bouffioux C, Sylvester R, van der Meijden AP, Oosterlinck W and Brausi M: Treatment of superficial bladder tumors: achievements and needs. The EORTC Genitourinary Group. Eur Urol 37: 1-9, 2000.

2. Kurth KH, Denis L, Bouffioux C, Sylvester R, Debruyne FM, Pavone-Macaluso $\mathrm{M}$ and Oosterlinck W: Factors affecting recurrence and progression in superficial bladder tumors. Eur $\mathbf{J}$ Cancer 31A: 1840-1846, 1995.

3. Malmstrom PU, Busch C and Norlen BJ: Recurrence, progression and survival in bladder cancer. A retrospective analysis of 232 patients with greater than or equal to 5-year follow-up. Scand J Urol Nephrol 21: 185-195, 1987.

4. Herr HW, Badalament RA, Amato DA, Laudone VP, Fair WR and Whitmore WF Jr: Superficial bladder cancer treated with bacillus Calmette-Guérin: a multivariate analysis of factors affecting tumor progression. J Urol 141: 22-29, 1989.

5. Millan-Rodriguez F, Chechile-Toniolo G, Salvador-Bayarri J, Palou J, Algaba F and Vicente-Rodriguez J: Primary superficial bladder cancer risk groups according to progression, mortality and recurrence. J Urol 164: 680-684, 2000.

6. Holmang S, Hedelin H, Anderstrom C and Johansson SL: The relationship among multiple recurrences, progression and prognosis of patients with stages Ta and T1 transitional cell cancer of the bladder followed for at least 20 years. J Urol 153: 1823-1827, 1995

7. Al-Sukhun S and Hussain M: Molecular biology of transitional cell carcinoma. Crit Rev Oncol Hematol 47: 181-193, 2003.

8. Theodorescu D: Molecular pathogenesis of urothelial bladder cancer. Histol Histopathol 18: 259-274, 2003. 
9. Dalesio O, Schulman CC, Sylvester R, De Pauw M, Robinson M, Denis L, Smith P and Viggiano G: Prognostic factors in superficial bladder tumors. A study of the European Organization for Research on Treatment of Cancer: Genitourinary Tract Cancer Cooperative Group. J Urol 129: 730-733, 1983.

10. Cai T, Margallo E, Nesi G, Giubilei G, Rizzo M and Bartoletti R: Prognostic value of static cytometry in transitional cell carcinoma of the bladder: recurrence rate and survival in a group of patients at 10 years follow-up. Oncol Rep 15: 213-219, 2006.

11. Streeter EH and Harris AL: Angiogenesis in bladder cancerprognostic marker and target for future therapy. Surg Oncol 11: 85-100, 2002.

12. Bochner BH, Cote RJ, Weidner N, Groshen S, Chen SC, Skinner DG and Nichols PW: Angiogenesis in bladder cancer: relationship between microvessel density and tumor prognosis. J Natl Cancer Inst 87: 1603-1612, 1995.

13. Offersen BV, Knap MM, Marcussen N, Horsman MR, Hamilton-Dutoit $\mathrm{S}$ and Overgaard J: Intense inflammation in bladder carcinoma is associated with angiogenesis and indicates good prognosis. Br J Cancer 87: 1422-1430, 2002.

14. Flamm J and Benesch A: Tumor-associated mononuclear cell infiltrate and recurrence rate in the superficial urothelial carcinoma of the urinary bladder. Urol Int 41: 187-191, 1986.

15. Fujimoto Y, Hasegawa Y, Kato N, Sakai S, Kuriyama M, Kawada Y, Nishiura T, Takeuchi T and Isogai K: The study of infiltrating lymphocytes in the tissues of bladder carcinoma. Hinyokika Kiyo 29: 1037-1045, 1983.

16. Flamm J: The value of tumor-associated tissue inflammatory reaction in primary superficial bladder cancer. Urol Res 18: 113-117, 1990.

17. Kavanaugh DY and Carbone DP: Immunologic dysfunction in cancer. Hematol Oncol Clin North Am 10: 927-951, 1996.

18. McCarty WG: Principles of prognosis in cancer. JAMA 96: 30-33, 1936.

19. Takeuchi H, Maehara Y, Tokunaga E, Koga T, Kakeji Y and Sugimachi K: Prognostic significance of natural killer cell activity in patients with gastric carcinoma: a multivariate analysis. Am J Gastroenterol 96: 574-578, 2001.
20. UICC International Union Against Cancer. TNM classification of malignant tumors. 6th edition. Wiley-Liss, New York, pp199-202, 2002 .

21. Mostofi FK, Sobin LH and Torloni H: Histological typing of urinary bladder tumors. Geneva, World Health Organization, 1973.

22. Oosterlinck W, Lobel B, Jakse G, Malmström P, Stöckle M and Sternberg C (The EAU Working Group on Oncological Urology): Guidelines on Bladder Cancer. Eur Urol 41: 105-112, 2002.

23. Heney NM, Ahmed S, Flanagan MJ, Frable W, Corder MP, Hafermann MD and Hawkins IR: Superficial bladder cancer: progression and recurrence. J Urol 130: 1083-1086, 1983.

24. Ropponen KM, Eskelinen MJ, Lipponen PK, Alhava E and Kosma V: Prognostic value of tumour-infiltrating lymphocytes (TILs) in colorectal cancer. J Pathol 182: 318-324, 1997.

25. Chouaib S, Asselin-Paturel A, Mami-Chouaib F, Caignard A and Blay JY: The host-tumor immune conflict. From immunosuppression to resistance and destruction. Immunol Today 18: 493-497, 1997.

26. Flamm J: Tumor-associated tissue inflammatory reaction and eosinophilia in primary superficial bladder cancer. Urology 40: 180-185, 1992.

27. Sarma KP: The role of lymphoid reaction in bladder cancer. J Urol 104: 843-849, 1970.

28. Stöber U: Der Einfluss der Lymphozyteinfiltration im Tumorgewebe auf Zeitpunkt und Infiltrationstendenz von Blasenkarzinomrezidiven. Urologe (A) 17: 296, 1978.

29. Bohle A: BCG's mechanism of action - increasing our understanding. For the EBIN Group. Eur Urol (suppl 1): 1-8, 2000.

30. Bartoletti R, Cai T, Nesi G, Sardi I and Rizzo M: Qualitative and quantitative analysis of angiogenetic factors in transitional cell bladder carcinoma: Relationship with clinical course at 10 years follow-up. Oncol Rep 14: 251-255, 2005.

31. Ishigami S, Natsugoe S, Tokuda K, Nakajo A, Che X, Iwashige H, Aridome K, Hokita S and Aikou T: Prognostic value of intratumoral natural killer cells in gastric carcinoma. Cancer 88: 577-583, 2000. 